\title{
O professor da educação básica como formador de seus pares: possibilidades para a profissionalização docente
}

\author{
Clayton José Budin* \\ Flavia Medeiros Sarti**
}

\begin{abstract}
Resumo
O artigo focaliza o papel e o lugar que os professores de Educação Básica desempenham e podem desempenhar na formação continuada docente, elegendo como referencial empírico Grupos de Formação (GF) organizados em uma rede municipal de ensino, nos quais professores da Educação Básica exercem o papel de formadores de seus pares. A pesquisa organizou-se por procedimentos de análise documental e entrevistas semiestruturadas com sujeitos envolvidos com os GFs. As análises realizadas destacam representações relativas à figura dos professores-formadores no que se refere à caracterização de sua atuação junto aos professores e seu papel no trabalho formativo. Evidencia-se a existência de um lugar bem definido para esses formadores, afinado com o processo de profissionalização do magistério. No entanto, os dados apontam também para certas fragilidades que se impõem à atuação desses formadores de professores, dificultando-lhes a ocupação de um lugar mais central na formação docente daquele município.
\end{abstract}

Palavras-chave: Formação de Professores. Formadores de professores. Comunidades de aprendizagem.

\footnotetext{
* Mestre em Educação pela Universidade Estadual Paulista (Unesp), campus de Rio Claro/SP. Professor de Geografia das redes municipais de ensino de Campinas/SP e Valinhos/SP.

** Doutora em Educação pela Universidade de São Paulo (USP). Professora do Departamento de Educação da Universidade Estadual Paulista (UNESP), campus de Rio Claro/SP.
} 


\section{Introdução}

Inadequações relativas à formação dos professores brasileiros têm constituído temática de amplo alcance nos discursos que, provenientes de diferentes áreas e espaços sociais, buscam identificar caminhos para a superação dos múltiplos problemas educacionais enfrentados em nosso país. Entre esses discursos, estão aqueles amparados pelo "argumento da incompetência" dos professores (SOUZA, 2006), segundo o qual os professores têm sido responsabilizados pelo baixo desempenho no que se refere à aprendizagem dos alunos. Mudar a educação escolar passaria, então, por uma "reinvenção" dos professores (BUENO, 2007). Seguindo essa perspectiva de grande impacto nas políticas educacionais das últimas décadas, a presumida incompetência dos professores - gestada por uma formação inicial ineficiente - deve ser sanada por meio do investimento na fomação continuada, assumida como solução (em muitos casos, única) para a superação dos problemas que afetam a educação escolar. Assim, consideráveis investimentos públicos têm sido feitos na formação de professores (MELO, 1999; SOUZA, 2006; GATTI, 2011), sem que nos atentemos para o alerta feito por Azanha (1995), de que as transformações centradas no professor não bastam para mudar as práticas escolares, havendo necessidade de mudanças mais amplas, envolvendo toda a estrutura educacional.

Se, por um lado, como previu Azanha (1995), nossos investimentos em formação docente não vêm rendendo as esperadas transformações na aprendizagem dos alunos brasileiros, de outro, acabaram por fomentar um amplo e diversificado "mercado de formação" (AUTOR 2, 2014) que, ancorado em trocas simbólicas (BOURDIEU, 1996), volta-se aos professores. Tal mercado tem sido amparado por discursos ligados à profissionalização do magistério (NÓVOA 1992, 1999; BOURDONCLE, 2000; TARDIF, 2000; IMBERNÓN, 2011 ; ALTET; PASQUAY; PERRENOUD, 2003), embora, paradoxalmente, venha reservando aos professores lugares periféricos, que lhes conferem pouco poder no "jogo da formação" (AUTOR 2, 2012) que então se configura.

Tendo em vista esse cenário paradoxal, as discussões aqui apresentadas resultam de uma pesquisa que teve por objetivo identificar possibilidades ligadas ao lugar e aos papéis dos professores de Educação Básica nesse espaço mercadológico da formação docente. Os resultados discutidos partem dos seguintes questionamentos: que papel os professores da Educação Básica podem desempenhar na formação de seus pares em um contexto marcado por discursos vinculados à profissionalização do magistério?

Um lugar de maior destaque para os professores no espaço da formação docente constitui demanda apontada já há algumas décadas na literatura educacional. Nas palavras de 
António Nóvoa (1992, p. 14):

É importante a criação de redes de (auto)formação participada, que permitam compreender a globalidade do sujeito, assumindo a formação como um processo interactivo e dinâmico. A troca de experiências e a partilha de saberes consolidam espaços de formação mútua, nos quais cada professor é chamado a desempenhar, simultaneamente, o papel de formador e de formando.

Mas, em que pese a proliferação discursiva em torno da necessidade de se valorizar as experiências dos professores e de possibilitar-lhes uma maior participação no processo formativo de seus pares, o efervescente mercado organizado em torno da formação docente (NÓVOA, 1999; MAUÉS, 2003; AUTOR 2, 2012) tem relegado os professores a um papel passivo, de meros consumidores de produtos formativos.

Novamente com Nóvoa (1999), observa-se nas últimas décadas um excesso de discursos sobre a centralidade do papel desempenhado pelos professores nos processos de ensino e aprendizagem escolar. No entanto, alerta o autor, esse excesso discursivo vem produzindo uma paradoxal pobreza no que se refere aos programas de formação docente, às políticas e práticas pedagógicas e à colegialidade docente.

Nessa direção, Cunha (2005) esclarece que o modelo convencional de formação continuada dos professores vem sendo bastante questionado nos últimos anos, no que se refere à sua eficácia quanto à qualificação e avanços para o trabalho docente. Tais questionamentos ressaltam a pouca contribuição desse modelo formativo para o desenvolvimento e a profissionalização docente.

Muito tem se enfatizado sobre o valor dos saberes produzidos na docência, mas os professores têm participado timidamente do jogo da formação docente atuando muito pouco na formação inicial e permanente de seus pares. É o que (AUTOR 2, 2012) busca demonstrar por meio de um esquema de triangulação sobre os agentes que atuam na formação docente. Cada um dos vértices do "triângulo da formação docente" seria ocupado por agentes específicos: professores de Educação Básica; universidades (especialistas da área); e o poder público (Estado como provedor e regulador das políticas públicas). As discussões empreendidas em torno das relações estabelecidas entre esses vértices da formação apontam para a passividade assumida pelos professores da Educação Básica em um contexto em que a universidade e o Estado ocupam lugares mais privilegiados, definindo e produzindo a formação docente. Nesse cenário, restaria ao professor da escola o "papel do morto" (em analogia ao jogo de bridge), caracterizado pelo consumo das políticas e produtos formativos que lhes são dirigidos pelos jogadores mais ativos e poderosos.

Essa situação choca-se com o processo de profissionalização do magistério básico, intentado nas últimas décadas (NÓVOA 1992, 1999; BOURDONCLE, 2000; TARDIF, 2000; IMBERNÓN, 2011; ALTET; PASQUAY; PERRENOUD, 2003), que, entre outros fatores, prevê mudanças significativas na formação docente, com a emergência de um modelo profissional de formação (em 
oposição a uma formação de natureza geral e acadêmica) em que os professores assumem participação mais ativa e maior poder (BOURDONCLE, 2000; ALTET et al., 2009).

Trata-se de uma formação que possibilite a constituição de uma "cultura de colaboração" (IMBERNÓN, 2010, p. 23) entre os professores, no sentido da conquista de maior autonomia profissional. Deste modo, os professores passariam a ocupar um lugar "próprio" (CERTEAU, 1994) na formação das novas gerações docentes, no caso da formação inicial, e na formação de seus pares na formação continuada e em serviço. Se pensado sob a perspectiva de Michel de Certeau (1994, p. 99), a delimitação por parte dos professores desse lugar "próprio" na formação docente permitir-lhes-ia "capitalizar vantagens conquistadas, preparar expansões futuras e obter assim para si uma independência em relação à vulnerabilidade das circunstâncias”.

No entanto, como ressalta Zeichner (2000, p. 14), a formação de professores "não recebe a importância devida para que se façam as coisas que precisam ser feitas, que podem ser feitas". Nessa direção, Nóvoa (2011) alerta que a maioria dos programas de formação vem apresentando pouca utilidade para os professores, visto que, de maneira geral, são cursos generalistas voltados para o professor enquanto indivíduo, apenas como uma "atualização" profissional, de maneira que não têm contemplado práticas baseadas no trabalho docente coletivo ou condizentes com a realidade e o contexto escolar de cada professor. O autor afirma que ações mais efetivas de formação de professores são aquelas organizadas pelos próprios docentes, por meio de um trabalho coletivo, com partilha e diálogo a respeito de suas práticas. Embora Zeichner e Nóvoa se refiram a contextos diferenciados, Estados Unidos e Portugal respectivamente, leitura semelhante pode ser feita no tocante ao contexto brasileiro. Assim, embora nos últimos anos tenhamos feito no Brasil considerável investimento em políticas formativas voltadas aos professores (GATTI, 2008), não temos logrado atender de fato às necessidades profissionais dos professores (GATTI, 2010).

Críticas, como as tecidas por Zeichner (2000), Nóvoa (2011), Cunha (2005) e Gatti (2010), sobre os estado atual dos investimentos na formação de professores, instigam-nos a conhecer experiências alternativas a esse respeito, nas quais os professores ocupem de fato um lugar de poder em sua formação profissional.

\section{Os professores em grupos de formação}

A busca por experiências formativas que apresentassem uma dimensão profissional mais efetiva nos levou aos “Grupos de Formação por Componente Curricular” (GFs) constituídos em uma rede municipal de ensino do interior paulista desde 1987. Atualmente, os GFs estão 
centralizados do Centro de Formação, Tecnologia e Pesquisa Educacional ligado à Secretaria Municipal de Educação (SME).

Semanalmente, esses grupos reúnem professores de um mesmo componente curricular, sob a coordenação de um colega, designado como “formador". A participação dos professores nos GFs é facultativa, mas incentivada pela administração municipal por meio de acréscimo na remuneração. Para viabilizar as reuniões semanais dos professores nos GFs, cada um dos grupos ocorre em um dia específico da semana, tendo duração de três horas/aula. Para efeitos de remuneração dos professores, é prevista uma quarta-hora aula como "atividade de estudo".

Segundo o assessor de currículo do Município, responsável pela organização dos GFs, esses grupos assumem um lugar de destaque entre as demais iniciativas de formação continuada implementadas no município, como possibilidade de uma formação mais diretamente articulada à prática docente e como espaço de socialização profissional dos professores. Ainda de acordo com o mesmo assessor, os formadores dos GFs assumem papel central para o desenvolvimento dessa formação profissional.

Seriam esses formadores dos GFs jogadores ativos no "jogo da formação docente" (AUTOR 2, 2012) estabelecido naquele município? Assumem de fato um lugar ("próprio") na formação de seus pares? Quem são esses professores, como são escolhidos entre os demais professores e o que se espera de sua atuação? E que representações eles têm sobre o papel que desempenham e como percebem seu lugar na formação docente? Essas questões nortearam uma investigação que teve por objetivo identificar e discutir, a partir do caso dos GFs, possibilidades da atuação dos professores de Educação Básica nos processos de formação docente.

A metodologia da pesquisa, cujos resultados finais são aqui apresentados, baseou-se em estudos documentais e entrevistas semiestruturadas. Foram examinados inicialmente documentos relativos à constituição e funcionamento dos GFs, por meio de publicações em Diários Oficiais do Município. Os dados então reunidos ofereceram subsídios para as atividades empíricas, desenvolvidas por meio de entrevistas que, por sua vez, possibilitaram obter informações mais específicas sobre a figura e o papel desempenhado pelos professores-formadores.

No total, foram realizadas dez entrevistas. Inicialmente, foram entrevistados individualmente os dois responsáveis pela seleção dos professores-formadores: a Coordenadora Setorial de Formação e o Assessor Técnico de Currículo. Ambos são coordenadores pedagógicos do município e, no período em que a pesquisa foi realizada (2012-2014), responsabilizaram-se pelos programas de formação continuada docente ali implementados. Além deles, foram entrevistados também, individualmente, os oito formadores (de cada componente curricular) então em atividade.

Os dados reunidos por meio desses procedimentos revelam aspectos interessantes sobre o papel dos formadores dos GFs, sobre os processos de seleção dos professores que assumem a 
função, sobre o modo como os formadores percebem sua própria atuação nesses grupos e, também, sobre os limites e possibilidades do lugar assumido por esses professores.

\section{Quem são os professores formadores e o que se espera de sua atuação nos GFs}

De acordo com os dados reunidos pela pesquisa, a seleção dos professores que assumem a função de formadores dá-se, inicialmente, por meio de indicação feita por diretores de escolas ou por outros agentes ligados ao ambiente escolar. Esses professores indicados são convidados pela Secretaria Municipal de Educação (SME) para uma entrevista, na qual se pretende verificar se eles de fato atendem aos critérios estabelecidos para ser um formador. Segundo os depoimentos reunidos por meio das entrevistas, tais critérios referem-se: 1. à qualidade do trabalho didáticopedagógico que desenvolvem junto aos alunos da Educação Básica; 2. à vinculação estável e intensa com a rede de ensino; 3. ao alto nível de formação acadêmica; 4. à capacidade de problematização da prática de ensino; e 5. a atitudes de liderança diante dos demais professores. Cada um desses cinco critérios aponta para certas expectativas que a SME nutre sobre o professorformador e sobre sua atuação junto aos GFs, como exposto a seguir.

\section{O professor-formador, antes de tudo um professor considerado excelente}

Os responsáveis pela escolha dos professores-formadores explicaram, em entrevista, que a qualidade do trabalho que estes últimos desenvolvem nas escolas costuma ter grande peso no processo de seleção para a função. Sobre esse processo de identificação de candidatos, a coordenadora setorial explica:

A gente tem a informação geralmente da escola, do orientador pedagógico, aquela pessoa que tem contato, aquela pessoa que desenvolve uma temática interessante, metodologias de trabalho diferenciado. (Coordenadora setorial de formação, entrevista, 2013).

Assim, tanto a coordenadora de formação quanto o assessor de currículo destacam que os professores selecionados para a função de formador devem ter a qualidade de sua atuação docente reconhecida pela Secretaria Municipal de Educação e por seus pares. Trata-se de professores que gozam de credibilidade para discutir as práticas, tendo em vista que eles mesmos se destacam pela proposição de ações pedagógicas diferenciadas em suas escolas de origem.

Ainda de acordo com a coordenadora setorial de formação, quando o professor realiza um trabalho distinto e reconhecido em sua escola, seja por uma proposta pedagógica com procedimentos menos convencionais, ou mesmo pela "didática" junto aos alunos, ele tende a ser 
convidado pela SME a socializar esse trabalho com os demais professores da rede municipal. Nesse caso, os GFs constituem-se espaços privilegiados para essa socialização de práticas e saberes docentes (o que ocorre também por meio da realização de oficinas pedagógicas e cursos de formação desenvolvidos pelos próprios docentes).

A importância atribuída à prática do professor para sua seleção como formador é evidenciada também pelo professor-formador de Matemática, que afirma ter sido convidado para a função pelo trabalho didático-pedagógico "diferenciado" que realiza com os alunos em sua unidade escolar.

\section{Uma vinculação estável e intensa com a rede de ensino: formador como "prata da casa"}

Além da qualidade de suas práticas pedagógicas, a forte vinculação com a rede municipal aparece como aspecto relevante para a escolha dos formadores. Os professores-formadores são efetivos da rede com largos anos de experiência. No caso dos formadores focalizados pela pesquisa, todos apresentavam à época mais de vinte anos de magistério, dos quais no mínimo 10 anos tinham sido dedicados àquela rede municipal. Segundo a coordenadora de formação, os professores geralmente preferem alguém da própria rede municipal para atuar como formador, pois enfatizam a importância da proximidade com a "realidade" cotidiana das escolas.

A esse respeito, a coordenadora enfatiza que "o professor-formador tem uma importância muito grande, eu acho que ele, em alguns momentos, é mais importante para o professor que faz e participa da escola, do que o professor da universidade [...]". E acrescenta: “[...] o nosso professor pede para que seja alguém próximo dele, próximo à realidade dele” (entrevista, 2013).

Essa vinculação dos formadores à rede de ensino é considerada por aqueles sujeitos como possibilidade de maior identificação por parte dos professores com a formação oferecida nos GFs. A coordenadora ressalta que os professores preferem alguém próximo ao cotidiano escolar para falar do trabalho docente. De seu depoimento depreende-se uma valorização dos saberes experienciais docentes (TARDIF, 2010), considerados por ela como importantes para o trabalho que os formadores realizam com professores já em exercício. Ela explica que "quando chamamos um professor de fora da rede para trabalhar na formação, os professores querem saber de onde ele veio, qual a experiência que ele tem de sala de aula" (entrevista, 2013).

O depoimento oferecido pela professora-formadora de Inglês segue nessa mesma direção: "para mim, tem extrema importância o Grupo de Formação, e tem que ser com professores da rede para a rede!". A formadora aponta, também, grande expectativa dos demais professores com relação ao trabalho do formador. Ela afirma que os professores participantes do GF parecem "confiar" nela por ser alguém que conhece a "realidade" da rede. 


\section{Um alto nível de formação acadêmica}

Outra característica que se impõe para a seleção do professor-formador refere-se ao nível de formação acadêmica. Os formadores que estavam em atuação nos GFs no período de realização da investigação apresentavam uma significativa inserção acadêmica. À exceção do professor-formador de História, todos eram pós-graduados. Os professores-formadores de Matemática, Artes, Ciências, Geografia e Inglês eram mestres. No caso dos formadores de Ciências e de Matemática, o mestrado havia sido realizado em um Programa de Pós-graduação em Educação. As formadoras de Inglês, Artes e Geografia haviam realizado o curso de mestrado junto a programas vinculados a suas disciplinas de referência, mas sempre focalizando temas relativos ao ensino. O formador de Língua Portuguesa realizou o mestrado em Programa vinculado à área de Educação (Ensino, Avaliação e Formação de Professores) e estava se doutorando em um Programa de Linguística Aplicada; enquanto o formador de Educação Física era mestre em Educação Física e doutor em Ciências do Esporte, atuando também como professor universitário.

A esse respeito, a coordenadora de formação enfatiza a importância atribuída pela SME às relações que o candidato a formador estabelece com a pesquisa e o ambiente acadêmico:

Algo que chame a atenção, por exemplo, o professor que fez o mestrado dele, que está dentro de uma temática importante, vamos convidá-lo para vir trabalhar aqui na formação. Aquilo que a Secretaria da Educação está achando que realmente vale a pena, então a gente chama aquele professor. O mestrado, o doutorado ou até o TCC com um tema interessante. (Coordenadora setorial de formação, entrevista, 2013).

Tal como pode ser apreendido do depoimento da coordenadora, além dos títulos acadêmicos, importa que as experiências vividas na universidade estejam relacionadas a temáticas consideradas pela SME como "interessantes"/“importantes" para o funcionamento do GF. Pressupõe-se que esses trabalhos possam subsidiar os estudos realizados pelos professores no Grupo e suas reflexões sobre as práticas pedagógicas. Neste mesmo sentido, o assessor de currículo destaca que o GF, por meio do trabalho do professor-formador, configura-se como espaço de estudo e de formação, articulando conhecimentos de natureza teórica, produzidos e veiculados no ambiente acadêmico, com saberes mais diretamente vinculados à prática docente.

\section{A capacidade de problematização e reflexão da prática de ensino}

De acordo com o relato do assessor técnico de currículo, o grande diferencial dos Grupos de Formação para os demais cursos de formação oferecidos pela própria Secretaria Municipal de Educação consiste justamente nessa ênfase em uma articulação mais efetiva entre teoria e prática 
docente. Para ele, tal articulação seria facilitada pelo fato de o formador ser também professor de carreira, atuante na rede de ensino e, ao mesmo tempo, alguém com significativas experiências acadêmicas.

A prática docente é enfatizada como um dos eixos de articulação dos GFs, que são assumidos como espaços de formação continuada, em relação estreita com a escola. Nos GFs, espera-se que os professores partilhem suas experiências, reflitam sobre suas práticas, debatam sobre propostas pedagógicas e vivenciem momentos formativos coletivos junto a seus pares.

Para o assessor de currículo,

Essa relação, essa apropriação que o professor que participa do GF faz, essa relação com o formador, com a teoria e com a prática, é o que acho que desenvolve uma formação ímpar, única, porque ela está diretamente ligada, direcionada à execução da sua prática. Então a formação tem tudo a ver, ela não fica fora, distante, a apropriação é rápida e muito significativa. (entrevista, 2013).

Para ele, o formador assume um papel de grande importância para a constituição dessa formação vinculada à vida da escola, posto que são professores "de carreira", atuantes na sala de aula e, portanto, agentes com recursos para realizar articulações entre teorias e práticas.

A professora-formadora de Inglês explicou que seu papel nos Grupos consiste em estimular esse "ir-e-vir" entre as discussões empreendidas naquele ambiente e a prática docente. Ressaltou, também, o potencial transformador que atribui a esse tipo de formação:

E mudou mesmo a cabeça deles. Nós trabalhamos com vários conceitos, novas abordagens do ensino de línguas. Então, era muito interessante ver os professores mais antigos mudando mesmo! "Nossa, professora, eu preciso um monte de coisa..." Mudança de paradigma mesmo. E isso eles levavam para o trabalho. [...] E eles traziam... "nossa eu tentei fazer isso que a gente fez no Grupo, até que eu tive um resultado, olha que legal!" Então eles estavam mais animados, a autoestima deles mudou muito, tudo isso mudou bastante. Então, se tivesse um maior ganho, era ver esses professores de Inglês, a autoestima boa, bacana. Eles descobriram que eles tinham voz na escola. (entrevista, 2013).

Alguns dos formadores também destacaram o fato de o GF proporcionar momentos de problematização sobre a prática docente, apontando assim para a figura do "professor reflexivo" (SCHÖN, 1997), tão presente nas últimas décadas na literatura sobre a formação docente. Desses depoimentos apreende-se a expectativa de que o formador do GFs assuma, diante dos professores, posturas e procedimentos formativos que lhes favoreça uma formação de teor reflexivo' ${ }^{1}$.

A professora-formadora de Geografia afirma a importância da formação continuada para possibilitar a reflexão sobre a prática e os modos pelos quais os professores podem melhorá-la: "Porque eu entendo a formação continuada como um momento de você pôr em prática. Por exemplo, primeiro, que você tem condições de refletir e pôr em prática sobre as coisas que você aprendeu" (entrevista, 2013). 
Nesse mesmo sentido, o professor-formador de Educação Física oferece informações sobre a organização do seu trabalho: "no Grupo de Formação são trabalhadas as dificuldades dos professores na sala de aula. São formados grupos de discussões, com debates que visam buscar soluções para os problemas e dificuldades da sala de aula" (entrevista, 2013).

Nesses depoimentos, o formador parece figurar com facilitador, incentivador e organizador dos processos reflexivos deflagrados entre os professores. Tal perspectiva destaca a importância de uma atuação formativa por parte do formador, tendo em vista que "a reflexão crítica não se concebe como um processo de pensamento sem orientação [...]", mas "[...] como um processo muito claro de definição perante os problemas e atuação consequente" (BORGES, 2002, p. 209).

O depoimento da professora-formadora de Inglês revela o modo como ela percebe sua intervenção junto ao grupo, de modo a possibilitar um ambiente propício à reflexão e ao trabalho em equipe. Diz ela: “então, eu achava que a gente tinha que se unir enquanto rede. [...] O primeiro trabalho que eu fiz foi unir esse grupo, as pessoas se conhecerem, todo mundo saber quem é quem" (entrevista, 2013). O mesmo é apontado pelo professor-formador de História, no que se refere a sua atuação com o grupo de professores:

A principal contribuição que eu vejo é o professor colocar suas dificuldades, discutir no grupo e perceber que ele não está sozinho. Perceber que nesta discussão ele pode afastar aquela ideia de "beco sem saída", quer dizer, tem alguém igualmente preocupado, igualmente angustiado. E, no diálogo, ele sempre enxerga alguma coisa, alguma luz. (entrevista, 2013).

A percepção desses professores segue no sentido apontado por Nóvoa (2011, p. 21). Segundo o pesquisador português, é a reflexão coletiva que dá sentido ao desenvolvimento profissional, “através dos movimentos pedagógicos ou das comunidades de práticas é que os professores avigoram o sentimento de pertencimento e identidade profissional”.

Ideias relativas às "comunidades de prática" (NÓVOA, 2011) ou "comunidades de aprendizagem profissional" (HARGREAVES, 2004) parece-nos bastante pertinentes para a caracterização do trabalho desenvolvido no interior dos GFs, baseado na partilha de experiências entre os professores. Nos GFs, os professores discutem o trabalho que realizam na escola, analisando conjuntamente suas estratégias de ensino e experiências junto aos alunos. Tal ambiente parece favorecer, como no caso das comunidades descritas por Hargreaves (2004), processos de “desenvolvimento profissional contínuo". Para o pesquisador americano, uma "comunidade profissional de aprendizagem une conhecimento, habilidades e disposições dos professores, em uma escola ou entre escolas, para promover aprendizagem e a melhoria compartilhadas" (HARGREAVES, 2004, p. 180). 
Atitudes de liderança diante dos demais professores e a possibilidade de um trabalho coletivo

A quinta característica identificada no perfil esperado dos formadores dos GFs diz respeito à capacidade de liderança. De acordo como o assessor de currículo:

Tem de aliar essa prática reconhecida como professor a essa prática de liderança. E, é claro, uma intencionalidade desse profissional em exercer esse trabalho. É um trabalho que exige muito, tem muita cobrança de seus pares, porque é um professor da rede como todos os outros, e esse trabalho com essa coordenação, essa liderança, requer realmente um perfil específico para ter a notoriedade, o respeito dessa turma. (entrevista, 2013).

A figura do formador, nesses termos, é identificada com a do coordenador, do organizador do trabalho dos GFs. Para tanto, deve liderar os professores e ser reconhecido por eles como um líder, uma autoridade.

Dos depoimentos reunidos apreende-se a expectativa de que os GFs assumam uma dimensão socioprofissional bem definida, de integração entre os professores participantes no que se refere à explicitação e discussão sobre as práticas de ensino. Para tanto, o formador assume papel de destaque, já que cabe a ele legitimar, de maneira geral, as atitudes de trocas entre os professores no grupo.

O professor-formador atuaria assim como "líder" diante dos professores que compõem o Grupo, favorecendo com sua atuação uma construção coletiva no trabalho formativo, de modo que os professores elaborem um sentimento de pertença a esse grupo profissional.

As professoras-formadoras de Geografia e de Inglês são mais enfáticas ao apontarem a questão do trabalho coletivo possibilitado pelo GF e o seu papel na união do grupo de professores, o que nos remete ao trabalho em equipe proposto por Nóvoa (1999) na formação docente, como elemento importante para a profissionalização do magistério. Segundo a formadora de Inglês:

Era um lugar onde eu sempre queria estar inicialmente, eu sempre quis trabalhar com formação de professores, era meu alvo. Porque eu via muita coisa que eu queria mudar. Então, eu achava que a gente tinha que se unir enquanto rede. [...] O primeiro trabalho que eu fiz foi unir esse grupo, as pessoas se conhecerem, todo mundo saber quem é quem... onde estava, manter esse primeiro contato. (entrevista, 2013).

A professora-formadora de Geografia aponta para uma mesma direção:

No Grupo de Formação a gente falava: Não... nós vamos tentar! Vamos fazer na nossa escola", "oh na minha escola eu vou fazer assim, porque tenho tais salas, que tem tal característica", "na minha escola não dá certo assim, mas eu acho que dá certo assim" Então, essa questão de tirar o professor do isolamento é muito importante. Inclusive, tirar o professor do isolamento, do ponto de vista didático, teórico-didático. (entrevista, 2013). 
Assim sendo, verifica-se a importância conferida pelos sujeitos entrevistados ao trabalho em equipe desenvolvido pelos GFs, e ao mesmo tempo, a relevância do papel desempenhado pelo professor de carreira, considerado líder dessas equipes.

Essa característica também está presente nas "comunidades de aprendizagem profissional" de Hargreaves (2004), pelo modo com que o trabalho em equipe exige uma "liderança local", que reconheça o contexto e a realidade da comunidade escolar. Para Hargreaves (2004, p. 182), é necessário que a pessoa que ocupa o cargo de coordenação em uma comunidade de aprendizagem tenha uma "liderança instrucional" promovida por meio de formação, orientação e instrução intensivas.

\section{Enfim... o professor formador se revela como expert no ensino e agente de socialização profissional}

A partir dos cinco aspectos acima reunidos, é possível afirmar que a figura dos formadores dos GFs está vinculada a, pelo menos, duas categorias centrais: os saberes docentes e a socialização profissional. No que se refere aos saberes docentes, os formadores dos GFs são reconhecidos e valorizados tanto em função dos saberes experienciais (TARDIF, 2010), produzidos no trabalho, quanto dos saberes disciplinares e da formação profissional, que trazem da vivência acadêmica. Nesse sentido, os professores-formadores de Matemática, Geografia, Artes e Ciências revelam em seus depoimentos que foram suas experiências profissionais em sala de aula que os levaram a ser formadores de seus pares.

Os processos de seleção dos formadores focalizados parecem ir ao encontro do pressuposto apontado por Tardif (2010, p. 21), para quem os saberes oriundos da experiência de trabalho cotidiana constituem "o alicerce da prática e da competência profissionais, pois essa experiência é, para o professor, a condição para a aquisição e produção de seus próprios saberes profissionais".

De acordo com a perspectiva apontada por Tardif (2010), é a partir desses saberes experienciais que os professores podem se tornar experts em seu campo de atuação. Esse parece ser o caso do formador de Língua Portuguesa que, segundo seu relato, é reconhecido na rede de ensino como “"o cara” da Língua Portuguesa” (entrevista, 2013).

A respeito da ideia de expertise, Galvão et al. (2011, p. 1017) esclarecem que ela "resultaria de uma trajetória de desenvolvimento individual que envolvia, especialmente, uma dedicação intensiva ao domínio escolhido". Seu desenvolvimento requer que o sujeito ultrapasse a percepção comum da prática profissional, reunindo condições de problematizá-la e, assim, produzir novos 
saberes em ação e para a ação. De acordo com Freidson (1998), a expertise é o que distingue a atuação profissional do trabalho amadorístico, afastando-se do senso-comum ligado à ocupação.

No caso aqui focalizado, o formador de Língua Portuguesa, dentre os demais entrevistados, é o que mais claramente parece reconhecer a si mesmo como um expert, aliando sua reconhecida atuação profissional ao discurso e à perspectiva acadêmica.

E o reconhecimento dessa expertise e da autoridade do formador por parte dos professores que participam do GF é compreendida pelos sujeitos focalizados como aspecto importante para realização do trabalho esperado, de socialização profissional docente.

A ideia de socialização profissional que emerge dos depoimentos reunidos aponta para perspectiva semelhante àquela apresentada por Dubar (2012), como um processo em construção permanente que conecta situações e percursos, tarefas a realizar e perspectivas a seguir, por meio de relações com outros e consigo mesmo. Ou seja, a socialização profissional ocorre por meio da partilha de conhecimentos e de experiências vivenciadas entre as pessoas do mesmo grupo profissional.

De acordo com a coordenadora de formação, um dos objetivos do Grupo de Formação é possibilitar um "espaço de trocas". Diz ela: "acho que o objetivo maior era esse mesmo, de estar socializando, podendo discutir, fazer a reflexão sobre uma temática” (entrevista, 2013).

A concepção de socialização profissional presente nos depoimentos aponta também para a necessidade de evitar o isolamento dos professores em suas escolas e salas de aula. Os GFs são percebidos pelos sujeitos como possibilidade de integrar-se a uma equipe de trabalho, com a formação e o apoio mútuo entre profissionais. Trata-se de um espaço onde se faz possível a “desprivatização das práticas”, categoria proposta por Cochran Smith (2012, p. 112) como

[...] a interrupção do ensino como um ato privado. A mudança é provocada por meio de uma variedade de perspectivas e processos que se abrem ao ensinar aos outros em colaboração, com outras pessoas que também estão envolvidos no esforço para fazer o seu trabalho público e aberto à crítica. A vantagem da desprivatização é o fim do isolamento, em vez disso, o apoio colegial, a articulação na construção do conhecimento, e o mútuo trabalho de colaboradores nas comunidades. (tradução nossa).

De acordo com os dados reunidos, os professores-formadores do GFs de Educação Física, de Geografia, de História e de Arte mostravam-se bastante envolvidos com objetivos voltados para esse processo de desprivatização.

Nesse sentido, é possível afirmar que processos de socialização profissional constituem parte central da dinâmica de trabalho que ocorre no interior dos GFs, reunindo elementos que os aproximam das "comunidades de aprendizagem profissional" sobre a qual se refere Hargreaves (2004). Tais comunidades, baseadas no trabalho conjunto dos professores, voltam-se para a melhoria do ensino e da aprendizagem, unindo "conhecimento, habilidades e disposições dos 
professores, em uma escola ou entre escolas, para promover a aprendizagem e a melhoria compartilhadas" (HARGREAVES, 2004, p. 180).

A constituição desse ambiente de trabalho, no caso dos GFs, é atribuído pelos sujeitos à atuação dos formadores, cujo trabalho tem em vista favorecer a socialização entre os professores. Os formadores entrevistados dizem se valer de suas experiências docentes em sala de aula para suscitar e subsidiar as discussões durante os encontros do Grupo.

Outro aspecto ligado às dinâmicas de socialização profissional nos GFs refere-se às reivindicações coletivas por melhores condições de trabalho e por valorização social. Nesse sentido, os processos de socialização profissional assumem um teor mais claramente político e podem favorecer, para os professores, a "compreensão do impacto das condições laborais, dos novos regulamentos educacionais, das exigências para o exercício do papel e da centralidade atribuída ao docente nos processos de mudança” (MUSSANTI, 2010, p. 2).

\section{O formador do GF, a profissionalização do ensino e o jogo da formação docente}

Os conteúdos associados ao papel desempenhado pelos formadores dos GFs, como experts docentes e agentes de socialização profissional, apontam para a convergência dessa figura com os discursos acerca da profissionalização docente.

Duas perspectivas atualmente associadas a uma formação de natureza mais profissional aparecem como nucleares nos Grupos de Formação, quais sejam: as lógicas da alternância (MONTEIRO; GIOVANNI, 2000, AUTOR 2) e do acompanhamento (ROQUET, 2009; AUTOR 2). A primeira elege a escola como lócus central da formação docente, enquanto a segunda aponta para a centralidade da atuação dos formadores de professores, sobretudo aqueles mais ligados à prática docente.

Essas perspectivas de formação procuram superar a tradicional dicotomia teoria-prática, articulando, sistematicamente, fundamentos e atividades do cotidiano dos professores. Nessa articulação, são consideradas e afirmadas as vozes, experiências e histórias pelas quais os professores atribuem sentido às suas práticas; os conceitos e procedimentos são aprendidos em meio às diferenças e ao diálogo com a experiência do outro e à teoria (MONTEIRO; GIOVANNI, 2000, p. 136).

No caso dos GFs, os entrevistados ressaltam a necessidade de articulação dos conhecimentos teóricos com a vivência prática, por meio de uma maior vinculação entre a escola e esses Grupos. Suas expectativas afinam-se ao discurso educacional mais atual que, como ressalta Autor 2 (2012, p. 218), caracteriza-se pela "importância que a experiência prática tem assumido 
para a formação, como meio de preparar melhor os professores para o trabalho docente [...]”, sendo cenário da "afirmação de uma modalidade formativa caracterizada pela alternância entre o local de formação e a escola" (grifos nossos).

Já no que se refere às práticas de acompanhamento, embora os professores-formadores dos GFs não acompanhem diretamente o trabalho dos professores em sala de aula, a lógica que sustenta essa perspectiva formativa mostra-se, de certo modo, presente em seu trabalho. Durante os encontros do GF, os professores são chamados a socializar suas práticas e reflexões, tendo o formador a oportunidade (senão a tarefa) de perceber as dificuldades, as estratégias e as práticas pedagógicas desenvolvidas e vivenciadas por esses professores. O processo de formação pode então ser vivido em seu dinamismo e perspectiva transicional, como indica Roquet (2009) quando discute a emergência do acompanhamento no campo da formação profissional.

Nos GFs, a experiência do acompanhamento é vivida na colegialidade, no seio de uma comunidade (“de prática", nos termos usados por Nóvoa, ou "de aprendizagem”, como estabelece Hargreaves). Esses grupos configuram-se como espaços de trabalho e de reflexão coletiva para os professores; o que, de acordo com Nóvoa (2011, p. 21), favorece "o sentimento de pertencimento e identidade profissional" docente. E, segundo os sujeitos entrevistados pela pesquisa, o papel do formador assume centralidade para essa integração entre os professores, em função de sua liderança e expertise docente.

Tem-se, portanto, que ao conferir centralidade à figura do professor como formador, os GFs, como modalidade formativa, revelam-se afinados aos discursos mais atuais sobre a profissionalização do magistério. Nesses grupos, os professores assumem um lugar bem definido na formação.

No entanto, certas fragilidades que se impõem à figura e à atuação desses formadores de professores lhes impedem de ocupar, nesse momento, um lugar "próprio", "do querer e do poder" (CERTEAU, 1994, p. 99) no cenário da formação docente daquele município. Os dados reunidos pela pesquisa aqui apresentada evidenciam precariedades quanto às condições em que os professores-formadores realizam seu trabalho nos GFs, o que lhes dificulta o desenvolvimento de uma identidade e uma profissionalidade (CONTRERAS, 2002) ligadas à formação docente. O trabalho como formador é exercido de maneira excedente à sua jornada convencional com os alunos. Assim, além das horas-aula destinadas ao trabalho docente, o professor-formador atua nos grupos de formação com horas excedentes. Esses professores teriam, além das 40 horas de trabalho docente, mais 4 horas/aula para coordenar o grupo de formação e 4 horas/aulas para a preparação das atividades como formador, totalizando 48 horas de trabalho semanal. Trata-se de uma jornada extenuante, em que a atuação do professor como formador do GF é considerada como um trabalho à parte aos vínculos trabalhistas com a rede. 
O excesso de trabalho a ser realizado por esses professores traz limites para o investimento que eles são capazes de realizar para o trabalho formativo. A atividade como formador, realizada junto a professores em exercício, apresenta demandas específicas que não se confundem com aquelas relativas ao trabalho docente com os alunos da Educação Básica. Requer a elaboração de saberes e procedimentos específicos da formação profissional e da formação de adultos, que pressupõem investimentos (de tempo, de estudos, etc.) por parte dos formadores.

Cabe ressaltar também a existência de uma instabilidade nos GFs com relação ao papel do formador. Alguns dos formadores entrevistados ressaltaram o caráter provisório de sua permanência na função. A rotatividade de formadores, vista por alguns como algo positivo (forma de oportunizar a experiência aos demais professores), também aparece como um dificultador para a composição de uma identidade específica como formador.

Mas, em que pesem as dificuldades que se impõem à afirmação dos professores como formadores de seus pares, experiências como a aqui focalizada parecem sugerir que, pouco a pouco, os professores deixam de ocupar o "lugar do morto" no campo da formação docente (NÓVOA, 1999; AUTOR 2, 2012). Avançam timidamente na delimitação de um lugar (próprio?) nesse campo e emergem como agentes da formação. Há entraves no caminho, disputas a serem travadas, mas, como visto, os professores estão no jogo.

\section{NOTAS}

1 As concepções dos informantes sobre a ideia de reflexão não serão objeto de análise no âmbito deste artigo. Cabe destacar, no entanto, que os depoimentos reunidos sugerem a existência de percepções bastante heterogêneas sobre esse tema por parte dos sujeitos focalizados.

\section{REFERÊNCIAS}

ALHEIT, P.; DAUSIEN, B. Processo de formação e aprendizagem ao longo da vida. Educação e Pesquisa. São Paulo, v. 32, n. 1, p. 177-197, jan./abr. 2006.

ALTET, M.; PAQUAY L.; PERRENOUD, P. (Orgs.) A profissionalização dos formadores de professores. Porto Alegre, Artmed, 2003.

AZANHA, J. M. P. Educação: temas polêmicos. São Paulo: Martins Fontes, 1995.

BORGES, R. de C. M. B. O professor reflexivo-crítico como mediador do processo de inter-relação da leitura-escrita. In: PIMENTA, S. G.; GHEDIN, E. Professor reflexivo no Brasil: gênese e crítica de um conceito. 2. ed. São Paulo: Cortez, 2002.

BOURDONCLE, R. Professionnalisation, formes et dispositifs. In: Recherche et Formation, n. 35, p. 117-132, 2000. 
BOURDIEU. P. A economia das trocas linguísticas: o que falar quer dizer. Tradução: Sérgio Miceli e outros. São Paulo: Edusp, 1996.

BUENO, B. O. É possível reinventar os professores? A "escrita de memórias" em um curso especial de formação de professores. In: SOUZA, E. C., ABRÃAO, M. H. (Orgs). Tempos, narrativas e ficções: a invenção de si. Porto Alegre/Salvador: EDIPUCRG/UFBA, v. 1, p. 219-238, 2007.

COCHRAN-SMITH, M. A Tale of Two Teachers: Learning to Teach Over Time. Kappa Delta Pi Record, v. 48, n. 3, 2012, p. 108-122.

CONTRERAS, J. A retórica do profissionalismo e suas ambiguidades. In: Autonomia de professores. São Paulo, SP: Cortez, p. 53-85, 2002.

CUNHA, J. E. da. Formação continuada de professores: tendências e perspectivas na formação docente no Brasil. In: Dominiun, Revista Científica da Faculdade de Natal, Ano III, v. 3, set./dez. 2005.

DUBAR, Claude. A construção de si pela atividade de trabalho: a socialização profissional. Cadernos de Pesquisa. [online]. 2012, v. 42, n. 146, pp. 351-367.

FREIDSON. E. Renascimento do profissionalismo - teoria, profecia e política. Trad, Celso Mauro Paciornik. São Paulo: Edusp, 1998.

FREITAS, H. C. L. de. Comentários. In: BALZANO, O. (Org.). O desafio da profissionalização docente no Brasil e na América Latina. - Brasília: CONSED, UNESCO, 2007. p. 18 - 19.

. Formação de professores no Brasil: 10 anos de embate entre projetos de formação. Educação \& Sociedade. Campinas, v. 23, n. 80, set. 2002, p. 137-168.

A (nova) política de formação de professores: a prioridade postergada. Educação \& Sociedade. Campinas, v. 28, n. 100, p. 1203-1230, out. 2007.

GALVAO, A.; PERFEITO, C.; MACEDO, R. Desenvolvimento de expertise: um estudo de caso. Rev. Diálogo Educ. 2011, v.11, n.34, p. 1015-1033.

GARCIA, M. M. A.; HYPOLITO, Á. M.; VIEIRA, J. S. As identidades docentes como fabricação da docência. Educação e Pesquisa, São Paulo, v. 31, n. 1, p. 45-56, 2005.

GATTI, B. A.; BARRETO, E. S. S.; ANDRÉ, M. E. D. D. Políticas docentes no Brasil: um estado da arte. Brasília: UNESCO, 2011.

GAUTHIER, C. Ensinar: ofício estável, identidade profissional vacilante, In: Por uma teoria da Pedagogia: pesquisas contemporâneas sobre o saber docente. Tradução: Francisco Pereira. Ijuí-RS: UNIJUÍ, 1998.

GOODSON, I. F. Mudança educativa e crise do profissionalismo. In: Conhecimento e vida profissional - estudos sobre educação e mudança. Porto: Porto, p. 209-221, 2008.

HARGREAVES, A. O ensino na sociedade do conhecimento: educação na era da insegurança. Porto Alegre: Artmed, 2004. 
IMBERNÓN, F. Formação docente e profissional: formar-se para a mudança e incerteza. Tradução: Silvana Cobucci Leite. 9. ed. São Paulo: Cortez, 2011.

GATTI. B. A. A formação dos docentes: o confronto necessário professor X academia. Caderno de Pesquisa, n. 81, maio 1992, p. 70-74.

. Formação de professores no Brasil: características e problemas. Educação \& Sociedade. Campinas, v. 31, n. 113, p. 1355-1379, out./dez. 2010.

GATTI, B. A.; BARRETO, E. S. S.; ANDRÉ, M. E. D. D. Políticas docentes no Brasil: um estado da arte. Brasília: UNESCO, 2011.

LÜDKE, M.; BOING, L. A. Caminhos da profissão e da profissionalidade docente. Educação \& Sociedade, Campinas, vol. 25, n 89, p. 1159-1180, set./dez. 2004.

MAUÉS, O. C. Reformas internacionais da educação e formação de professores. Cadernos de Pesquisa, n. 118, p. 89-118, 2003.

MONTEIRO, A. M. F. C. Professores: entre saberes e práticas. Educação \& Sociedade, ano XXII, $\mathrm{n}^{\mathrm{o}} 74$, abr. 2001.

MONTEIRO, D. C.; GIOVANNI, L. M. Formação Continuada de Professores: o desafio metodológico. Cap. 6. In: Educação continuada - reflexões e alternativas. MARIN, A. J. (Org.). Campinas-SP: Papirus, 2000.

MUSSANTI, S. I. Socialização profissional. In: OLIVEIRA, D. A.; DUARTE, A. M. C.; VIEIRA, L. M. F. DICIONÁRIO: trabalho, profissão e condição docente. Belo Horizonte: UFMG/Faculdade de Educação, 2010. CD-ROM.

NÓVOA, A. O regresso dos professores. Pinhais: Melo, 2011.

Formação de professores e profissão docente. In: Os professores e a sua formação. Lisboa: Dom Quixote, 1992, p. 13-33.

Os professores na virada do milênio: do excesso do discurso à pobreza das práticas.

Educação e Pesquisa, São Paulo, v. 25, n. 1, p. 11-20, jan./jun. 1999.

NUNES, C. M. F. Saberes docentes e formação de professores: um breve panorama da pesquisa brasileira. In: Educação \& Sociedade, ano XXII, nº 74, abr./2001, p. 27-42.

PIMENTA, S. G. Formação de professores - saberes da docência e identidade do professor. Revista Nuances, vol. III, p. 5-14, set. 1997.

ROQUET, Pascal. L'emergence de l'accompagnement. Une nouvelle dimension de la formation. Recherche et Formation, n. 62, p. 13-24, 2009.

TARDIF, M. Saberes profissionais dos professores e conhecimentos universitários - elementos para uma epistemologia da prática profissional dos professores e suas consequências em relação a formação para o magistério. Revista Brasileira de Educação, nº 13, 2000.

. Saberes Docentes e Formação Profissional. Petrópolis: Vozes, 2010. 
TARDIF, M.; RAYMOND, D. Saberes, tempo e aprendizagem do trabalho no magistério. Educação \& Sociedade, ano XXI, n. 73, dez. 2000.

TARDIF, M.; LESSARD, C. O ofício de professor - histórias, perspectivas e desafios internacionais. Tradução: Lucy Magalhães. Petrópolis, RJ: Vozes, 2008.

ZEICHNER, K. Formação de professores: contato direto com a realidade da escola. In: Revista Presença Pedagógica (Entrevista) v. 6 n. 34, jul./ago. 2000, p. 5-15.

WEBER, S. Profissionalização Docente e Políticas Públicas no Brasil. Educação \& Sociedade, v. 24, n. 85, Campinas-SP, p. 1125-1154, dez. 2003. 


\section{Teacher of Basic Education as educator of peers: possibilities for teachers professionalization}

\begin{abstract}
The article focuses on the role and the place that teachers of Basic Education play and can play in teaching continued education. The article elects as an empirical referencial Groups of Continued Formation organized in an educational municipal system, where teachers of Basic Education play a role as teacher-educators of their peers. The research was organized by procedures of documental analysis and semi-structured interview with individuals involved with the Groups of Continued Formation. The analysis that was carried out stood out representations related to the figure of the teacher-educators concerning the characterization of their practice with the teachers and their role in the formative work. The existence of a definite place for these teacher-educators, thinning to the professionalization of the teaching progress. However, the data also point to certain weakness that requires the performance of these teacher-educators, making it difficult for them to occupy a more central place in the teacher formation of that county.
\end{abstract}

Keywords: Teachers education. Teachers educators. Teachers professionalization

\section{Clayton José Budin}

E-mail: claytonbariri@gmail.com

Flavia Medeiros Sarti

E-mail: fmsarti@rc.unesp.br
Le professeur de l'ecole comme formateur de ses pairs: possibilités pour la professionnalisation de l'enseignement

\section{Résumé}

L'article focalise le rôle et le lieu que les professeurs des écoles jouent et peuvent jouer dans la formation continue des enseignants. Il élit comme référentiel empirique des. Groupes de formation (GFs) organisés par un réseau municipal des écoles, dans lequel des professeurs de l'éducation fondamentale jouent le rôle de formateurs de ses pairs. La recherche a été organisée par des procédures d'analyse documentale et par des entretiens semi-structurés avec des sujets impliqués dans les GFs. Les analyses réalisées surlignent des répartitions sur la figure des professeurs formateurs, concernant à la caractérisation de sa performance avec les autres professeurs et son rôle dans le travail formatif. Reste clair de l'existence d'un lieu bien précis pour ces formateurs, ce qu'est en conformité avec de processus de professionnalisation $\mathrm{du}$ professorat. En revanche, les données révèlent quelques fragilités associées au travail de ces formateurs, en mettant en difficulté l'occupation d'un lieu plus central au sein de la formation des enseignants dans cette ville.

Mots-clés: Formation de maîtres. Formateurs d'enseignants. Professionnalisation d'enseignants.

Enviado em: 23/03/2015

Versão final recebida em: 30/11/2016

Aprovado em: 22/12/2016 